\title{
Comment on: Hematopoietic stem cell transplant for erythropoietic porphyrias in pediatric patients
}

\author{
Satesh Kumar ${ }^{1}$ and Mahima Khatri ${ }^{2}$ \\ ${ }^{1}$ Shaheed Mohtarma Benazir Bhutto Medical College \\ ${ }^{2}$ Dow University of Health Sciences
}

October 6, 2021

TITLE PAGE

Letter to the editor:

-Comment on: Hematopoietic stem cell transplant for erythropoietic porphyrias in pediatric patients

-Authors:1. Satesh Kumar, 2.Mahima Khatri

-correspondence: Satesh Kumar, $4^{\text {th }}$ year MBBS student, Shaheed Mohtarma Benazir Bhutto Medical College Liyari, Karachi

Address: Parsa citi Block E Floor $5^{\text {th }}$ Flat 501 near police headquarter, Garden east Karachi.

Contact: +92-3325252902 Email: Kewlanisatish@gmail.com

Other author: Mahima Khatri, final year MBBS student, Dow university of Health sciences

Email: Mahimakhatri12333@gmail.com

-Word Count for: 484

Disclosure: none to declare

Conflict of interest: none to declare

Acknowledgements: none to declare

Comment on: Hematopoietic stem cell transplant for erythropoietic porphyrias in pediatric patients

To the editor:

We have read with great sincerity the article "Hematopoietic stem cell transplant for erythropoietic porphyrias in pediatric patients", YunZu M. Wang et al. ${ }^{1}$ It was a pleasure for us to read the concisely written article, and we congratulate the authors for their excellent efforts. The authors have succinctly written numerous scenarios. The final message of the article is that hematopoietic stem cell transplant (HSCT) rectifies the defective heme pathway and should be advised early in patients with severe erythropoietic porphyrias to minimize end-organ damage.

Based on varied research ${ }^{2,3}$ on this lethal disease, we agree that HSCT should be considered early in patients to minimize the damage caused by this condition and enable patients to live a healthy lifestyle. However, 
we would like to mention a few points that we feel would enhance the quality of this article and add to the existing knowledge of this congenital disease.

First, we speculate that the matching of samples would have drawn more meticulous results and increased the validity of the findings. The authors have not highlighted whether different mutations other than UROS exist. For instance, three male patients presented with the X-linked GATA1 gene mutation, an erythroid transcription factor on chromosome Xp11.23. ${ }^{2}$ Additionally, the study's retrospective nature has limited reporting regimens accordingly, such as case reports in 2004 elaborated proper doses per body weight and intervals, I.e., Thymoglobulin and Busulphan were given at $5 \mathrm{mg} / \mathrm{kg}$ per day and cyclophosphamide at $65 \mathrm{mg} / \mathrm{kg}$ per day as the conditioning regimen. ${ }^{4}$ Equivalently, prophylactic measures could have expatiated for the prevention of graft-versus-host disease. ${ }^{4}$ For illustration, patients were given cyclosporine infusion for 42 days with an initial dose of $(3 \mathrm{mg} / \mathrm{kg})$ followed by $6 \mathrm{mg} / \mathrm{kg}$ for six months orally to prevent any immunologic reaction to transplant.

Secondly, as it is established that the immune system of the pediatric population is not well developed, the authors should have mentioned if any workup for infectious etiologies was sent, such as TORCH (Toxoplasmosis, Syphilis, Rubella, Cytomegalovirus, Herpes simplex virus, and HIV) infections. ${ }^{5}$ Furthermore, with other factors such as any environmental exposure exaggerating possible porphyria, the authors must have provided data on their environment and surroundings since birth, considering it may also impact. Given the health concerns in the paediatrics population, varying ways could be quoted for differential diagnosis, such as a simple bedside method is wood lamp examination of the diaper or urine if available, for coral-red fluorescence. ${ }^{5}$ Positivity of tests could raise concerns for further investigation, such as porphyrin levels and genetic testing.

In addition to these, the authors could have commented on various other possible ways to avoid exposure to light, such as wearing sun-protective clothing and using window filters in cars and homes. ${ }^{2}$ Yet, that could have also negatively impacted children as sunlight is a natural source of vitamin D. Finally, different approaches should be used to improve investigations and treatments. New treatment concepts should be augmented so that other therapeutic options become employable.

\section{Reference}

1. Wang YM, Gloude NJ, Davies SM, Lucky AW, Nelson AS. Hematopoietic stem cell transplant for erythropoietic porphyrias in pediatric patients. Pediatric Blood E Cancer . 2021;68(9). doi:10.1002/pbc.29231

2. Erwin AL, Desnick RJ. Congenital erythropoietic porphyria: Recent advances. Molecular Genetics and Metabolism . 2019;128(3):288-297. doi:10.1016/j.ymgme.2018.12.008

3. Blouin J-M, Ged C, Lalanne M, et al. Iron chelation rescues hemolytic anemia and skin photosensitivity in congenital erythropoietic porphyria. Blood . 2020;136(21):2457-2468. doi:10.1182/blood.2020006037

4. Martinez Peinado C, Díaz de Heredia C, To-Figueras J, et al. Successful Treatment of Congenital Erythropoietic Porphyria Using Matched Unrelated Hematopoietic Stem Cell Transplantation. Pediatric Dermatology . 2013;30(4):484-489. doi:10.1111/pde.12117

5. Hogeling M, Nakano T, Dvorak CC, Maguiness S, Frieden IJ. Severe Neonatal Congenital Erythropoietic Porphyria. Pediatric Dermatology . 2011;28(4):416-420. doi:10.1111/j.1525-1470.2010.01376.x 